\title{
A REVIEW OF COMPONENTS AND CONFIGURATIONS OF SURVEY RESEARCH IN LEAN CONSTRUCTION
}

\author{
Kayvan Koohestani ${ }^{1}$, Mani Poshdar ${ }^{2}$, Sara Moayedi ${ }^{3}$, Patricia Tzortzopoulos ${ }^{4}$, \\ Saeed Talebi ${ }^{5}$, and Vicente A. González
}

\begin{abstract}
The reliability of research is substantially linked with its methodology and design. The use of surveys is one of the methods that has been commonly used in research projects. Therefore, identifying the active state and classification of the mechanisms used by the survey studies can help increase the quality of future research. Accordingly, this study reviews the survey literature on Lean Construction to identify their common components along with their configurations. To achieve this goal, a total number of seventy studies were randomly sampled from the publications pool and reviewed. Afterwards, their bibliographic and content characteristics were extracted and analysed and a total of seven common components as well as three dominant configurations were found. Through a thematic analysis, twelve main themes were identified which were further sorted by their observed frequency. The result shows the relationship between the themes and the configurations applied by the studies so far. It also discloses an overall status of the survey research in Lean Construction which can be used as a valuable lead for researchers to decide for the orientation and design of their future research projects.
\end{abstract}

\section{KEYWORDS}

Lean construction, literature review, research, survey.

\section{INTRODUCTION}

Following the advent of Lean Construction, a number of calls for reform in the construction industry have attracted many researchers from all over the globe to enhance construction productivity (Aziz and Hafez 2013; Ballard 2000; Egan 1998; Koskela and Howell 2002). Consequently, an increasing amount of theories, methods and practices have been introduced and their practical implications have been widely investigated

$1 \quad$ Freelance Researcher, Iran, koohestani@gmail.com, orcid.org/0000-0002-9988-3688

2 Lecturer, Built Envir. Engrg. Dept., Auckland Univ. of Technology, Auckland, New Zealand, mani.poshdar@aut.ac.nz, orcid.org/0000-0001-9132-2985

3 PhD Student, School of Art, Design and Architecture, University of Huddersfield, Huddersfield, HD1 3DH, UK, Sara.moayedi@hud.ac.uk, orcid.org/0000-0003-4349-6934

4 Professor, School of Art, Design and Architecture, University of Huddersfield, Huddersfield, HD1 3DH, UK, P.Tzortzopoulos@ hud.ac.uk, orcid.org/0000-0002-8740-6753

5 Sr Lecturer, School of Engineering and the Built Environment, Birmingham City University, Birmingham, UK, Saeed.Talebi@ bcu.ac.uk, orcid.org/0000-0001-6711-0931

6 Sr Lecturer, Department of Civil and Environmental Engineering, Founder and Research Lead Smart Digital Lab, The University of Auckland, 20 Symonds Street, Auckland, New Zealand, v.gonzalez@auckland.ac.nz, orcid.org/0000-0003-3408-3863 
through numerous studies (Ghosh and Young-Corbett 2009). Thus, a diverse range of methods and techniques have been applied by researchers to advance the various aspects of this field. Currently, conducting surveys has developed into a rigorous approach to research as a systematic method (Ponto 2015). According to the recognition-by-components theory, things should be broken down into their components to be recognized and understood (Biederman 1987). However, in the case of Lean Construction survey research, the authors have found no comprehensive study which was particularly focused on the common components used by the Lean Construction research community. This study seeks to partially close this gap by identifying and characterizing the common components and various classifications of research in Lean Construction from a sample of survey research on Lean Construction.

\section{SURVEY RESEARCH}

A survey is a type of field study, which collects data from a sample of individuals by answering a predetermined set of questions (Check and Schutt 2011; Rossi et al. 2013). The major steps of survey research are highlighted as below:

- Design and planning, which presents one of the crucial steps to identify requirements, limitations, and methods. In this step, the target sample is defined, the data collection method is determined, and measurement instruments are developed. The method is determined based on the specific survey requirements as well as time, cost and resource constraints (Abduh and Roza 2006).

- Data collection, where the researcher obtains the required information. Interviews and questionnaires are the most prevalent data collection approaches performed in survey research. Interviews can be conducted in structured, semi-structured or unstructured styles, and the sessions can take place by phone, computer or in person. The collected data can be qualitative or quantitative (Abduh and Roza 2006; Sapsford and Jupp 1996). Some studies may utilize a mix of both to increase the validity and reliability of the results (Hox and Boeije 2005).

- Lastly, analysis of the collected data, which eventually feeds into the key findings of the research (Alreck and Settle 1985; Singleton et al. 1999).

It should be noted that each step can involve further sub-steps that deserve in-depth exploration.

\section{RESEARCH METHOD}

At first, a total of 87 studies were selected using the search term "Lean Construction AND survey" on Google Scholar. The databased was employed to form a random sample and ensure the diversity in selections from different journals and conferences. Then, a screening step was applied in which a set of inclusion and exclusion criteria were used to refine the selection. The criteria embraced the studies that:

1. were published in the form of either a journal or conference paper

2. were published in the English language

3. were directly related to Lean Construction

4. fit into the definition of survey research

Therefore, after a round of skim and scan of the abstracts, research methods and conclusions, a total of 70 articles that met the above criteria were selected to go through 
the rest of the process. The next step investigated various aspects of the bibliographic information, data collection, analysis and themes used by the samples. The acquired data were coded in the NVivo software package (QSR International), which enabled the researchers to track the recurrence frequency of the coded items. During the review, the common components of the sampled survey research papers were identified and coded based on their main characteristics. Concurrently, various compositions of the main identified components were observed and grouped as study configurations. The study also conducted a content analysis using word frequency on the samples and reported the relationship between the themes and the contents. Finally, the research method and findings of the study were validated and confirmed by two researchers of the field whose demographic information is indicated in table 1 . In terms of reliability and validity, the paper highly complies with the strategies suggested by Noble and Smith (2015).

Table 1- Demographic information of the validators

\begin{tabular}{ccccc}
\hline $\begin{array}{c}\text { Research } \\
\text { Category }\end{array}$ & $\begin{array}{c}\text { Years of } \\
\text { Experience }\end{array}$ & $\begin{array}{c}\text { Level of } \\
\text { Education }\end{array}$ & Occupation & Age \\
\hline Expert 1 & 11 & PhD & $\begin{array}{l}\text { Associate } \\
\text { professor }\end{array}$ & 44 \\
Expert 2 & 14 & PhD & $\begin{array}{l}\text { Associate } \\
\text { professor }\end{array}$ & 49 \\
\hline
\end{tabular}

\section{SAMPLE INFORMATION}

To get a demographic grasp of the sample, the publications were classified based on the country of affiliation of their first author. In addition, a classification of developed and developing countries was made according to the United Nation's World Economic Situation and Prospects (2020).

In general, the papers were originated from 29 countries, including 19 developing and ten developed countries. Furthermore, although the figures indicate an average number of 2.4 publications per country, the distribution between developing and developed countries was not uniform. Figure 1 demonstrates the spread of the samples over time and the classification of their country of origin. It presents an increase in the frequency of the use of survey research in Lean Construction. The overall trend shows that the surge can be seen in both developing and developed countries. Furthermore, India with seven and UK with 12 publications were identified as the most prolific countries among developing and developed countries, respectively.

As for the publication medium, a statistical analysis of the published sources indicates that the sample was comprised of 39 journal and six conference titles. The Annual Conference of International Group for Lean Construction (IGLC) and Lean Construction Journal had the biggest share of the publications in the studied samples. Yet, journal papers constituted 51 studies which account for $73 \%$ of the sample. 


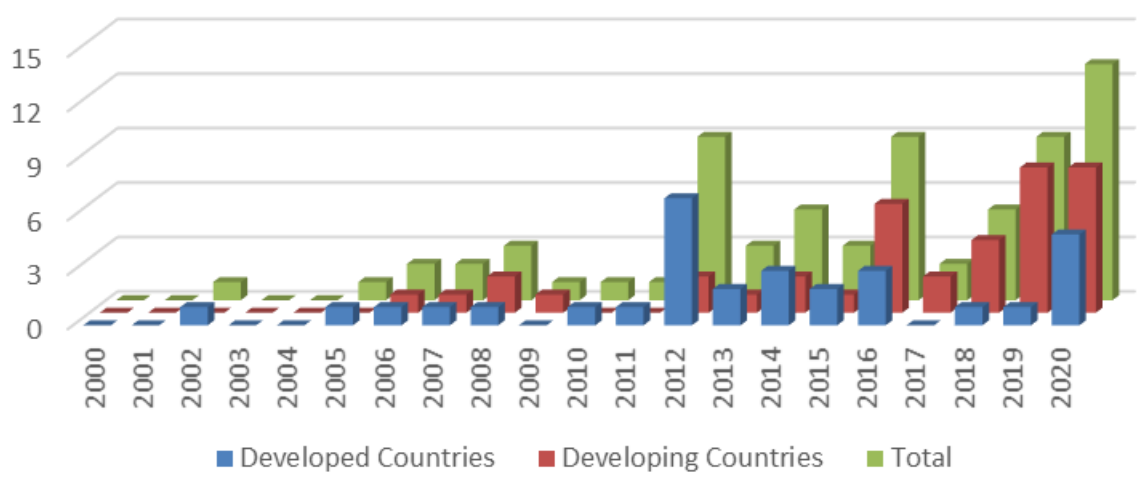

Figure 1- Distribution by year and category of their first authors' country

\section{COMMON COMPONENTS OF THE STUDY DESIGNS}

The analysis of the records indicated that an extended map of the study designs used by the survey-based research in Lean Construction is composed of the seven following components:

1. Research concept development: It justifies the gap, undertakes literature review to identify state of the art, provides a clear statement for the research problem(s) and research question(s). This step was present in all of the reviewed publications.

2. Pre-design field exploration: It is comprised of collecting the data required to formulate or complete a further step in a study. For instance, in many cases, the pre-design field exploration was used to devise questionnaires or design interviews. Almost $90 \%$ of the studies involved pre-design field exploration that was conducted based on literature reviews, interviews, observations and questionnaire surveys in the order of their frequency. The associated data was found to be of qualitative nature except in one case that quantitative data was collected using a questionnaire survey (Abduh and Roza 2006; Koohestani et al. 2020; Li et al. 2019).

3. Study design: this step was performed to design or formulate further steps of a study. In the majority of cases, this component involved designing a questionnaire or interview. Almost $90 \%$ of the publications included this step in their design. The majority of those that omitted this component used unstructured interviews that did not require a specific design (Abduh and Roza 2006; Bashir et al. 2013; Bygballe and Swärd 2014; Enshassi and Abu Zaiter 2014; Jasmine and Vasantha 2007).

4. Data collection: this was the main data collection phase upon which the findings were drawn. Therefore, it was present in all of the studies. Primary data was collected using questionnaire surveys and interviews in the majority of the cases. Other methods such as direct observations, archival review and the use of organizational databases were also utilized by this research component (Bashir et al. 2013; Enshassi and Abu Zaiter 2014; Meng 2019). The collected data were of both qualitative and quantitative nature. Nevertheless, Quantitative data was more frequent. Furthermore, in $11 \%$ of the cases, a combination of both types of data was collected (Figure 2). 


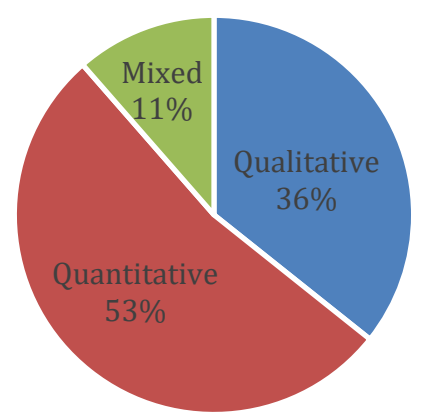

Figure 2- Types of main data in the sampled research

5. Data analysis: A wide range of methods were used to discover information and to make meaningful insight out of the collected data. They varied depending on the nature of the data. Yet, thematic and statistical analysis were the most prominent methods of analysing the qualitative and quantitative data, respectively. Similar to data collection, this component was also present in all of the reviewed studies (Bygballe and Swärd 2014; Enshassi and Abu Zaiter 2014; Koohestani et al. 2020).

6. Describing the phenomenon: This component would describe the observed patterns in the studied phenomenon. It was particularly focused on the "what" s rather than "why" s. This component was also observed in all of the sampled literature.

7. An in-depth explanation of the phenomenon: existed in $10 \%$ of the reviewed samples. It would develop a model, framework or approach (Li et al. 2019).

Figure 3 presents a general map of the typical arrangement of these seven components in Lean Construction survey research. The range of specific configurations used by the researchers is introduced and elaborated in the forthcoming sections.

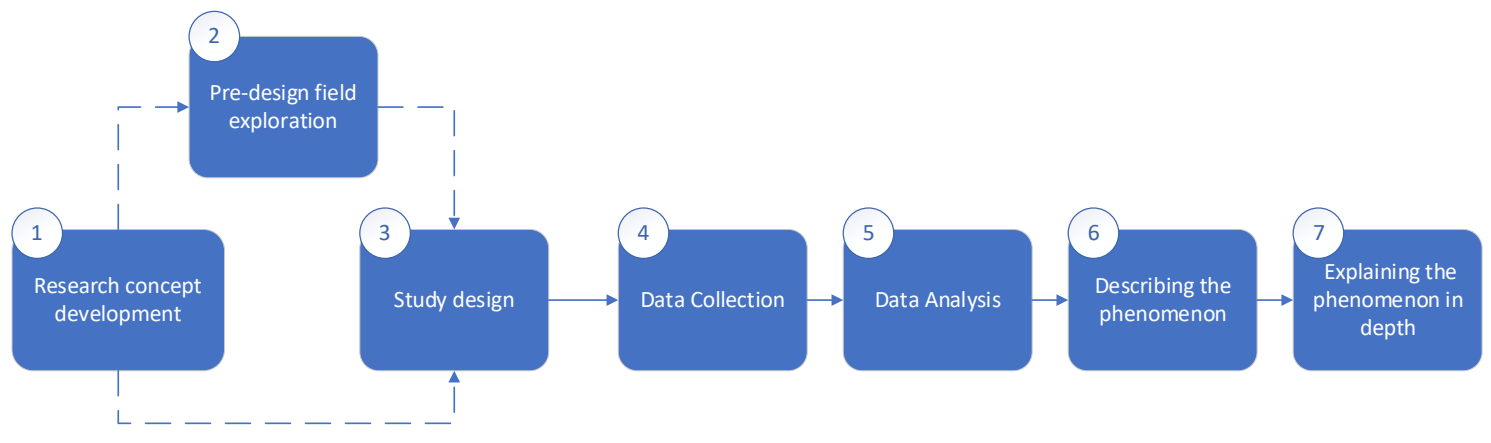

Figure 3- Identified common components of the study designs

\section{RESEARCH CONFIGURATIONS}

As explained, the use of the identified components varied by the structure and design of the reviewed studies. Accordingly, three different configurations were identified (Table 2 ) which include simple, semi-elaborated and elaborated configurations. As the table shows, five components were an integral part of all three configurations. The integral components were identified as the research concept and development (comp \#1), study design (comp \#3), data collection (comp \#4), data analysis (comp \#5), and describing the phenomenon (comp \#6). However, what differentiated between the three configurations was the inclusion of the other two components. While the simple category did not involve 
any pre-design field exploration (comp \#2) and explanation of the phenomenon (comp \#7), the semi-elaborated category had component \#2 added to its structure, and the elaborated category involved all the seven identified components.

Table 2- The difference between the configurations

\begin{tabular}{|c|c|c|c|c|c|c|c|}
\hline $\begin{array}{l}\text { Research } \\
\text { Category }\end{array}$ & $\begin{array}{c}\text { Comp } \\
\# 1\end{array}$ & $\begin{array}{c}\text { Comp } \\
\# 2\end{array}$ & $\begin{array}{c}\text { Comp } \\
\# 3\end{array}$ & $\begin{array}{c}\text { Comp } \\
\# 4\end{array}$ & $\begin{array}{c}\text { Comp } \\
\# 5\end{array}$ & $\begin{array}{c}\text { Comp } \\
\# 6\end{array}$ & $\begin{array}{c}\text { Comp } \\
\# 7\end{array}$ \\
\hline Simple & $\mathrm{Y}^{1}$ & $\mathrm{~N}^{2}$ & $\mathrm{Y} / \mathrm{N}^{3}$ & Y & Y & Y & $\mathrm{N}$ \\
\hline Semi-Elaborated & Y & Y & $\mathrm{Y} / \mathrm{N}$ & Y & Y & Y & $\mathrm{N}$ \\
\hline Elaborated & Y & Y & Y & Y & Y & Y & $\mathrm{Y}$ \\
\hline
\end{tabular}

\section{CONTENT ANALYSIS}

The findings of the publications were also thematically analysed and categorized into twelve groups. Figure 4 indicates the identified themes and their share in the studied sample. As can be seen, Lean Construction implementation barriers, benefits and success factors were the most recurring themes in the sample.

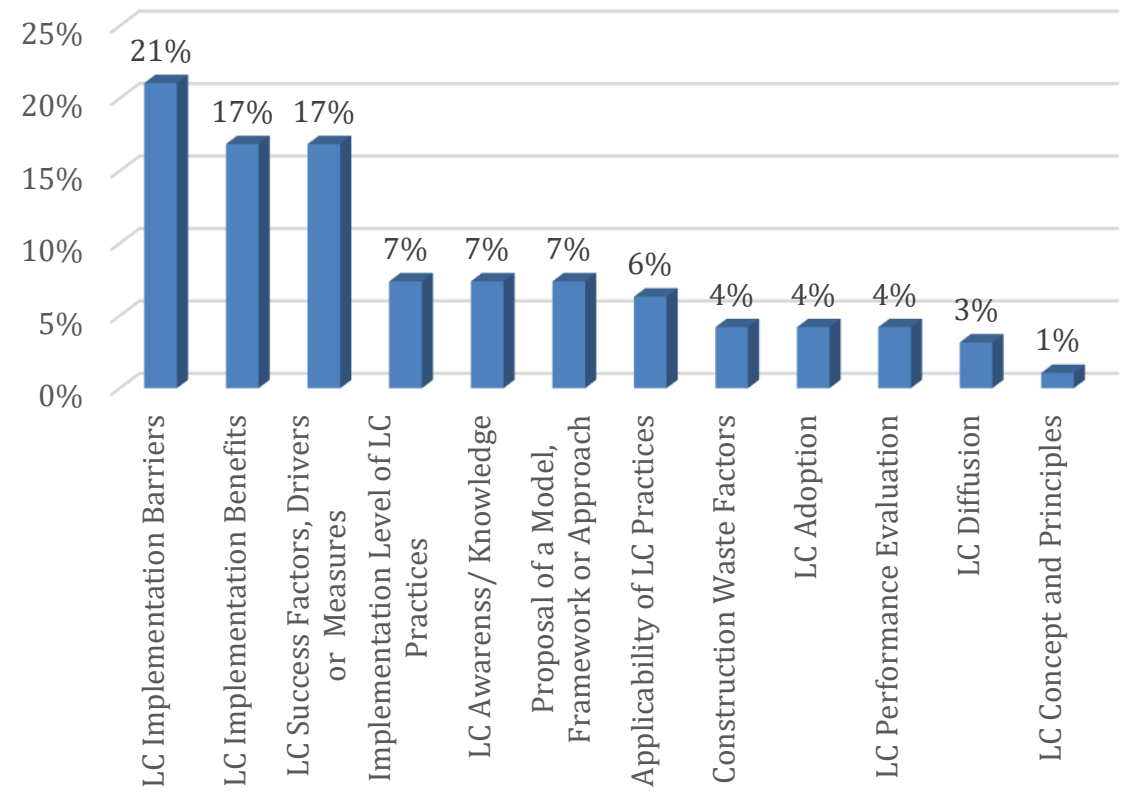

Figure 4- Themes of findings

The study also undertook a word frequency analysis which presents an effective method to obtain context and trends out of textual content (Zhong and Song 2008). Therefore, the 50 most frequent words in the sample were identified and visualized in the form of a word cloud (Heimerl et al. 2014) in figure 5. Management, implementation, safety and production were the most frequent words in declining order. Process, barriers, waste, performance, and value were the next most frequent words. These results are in harmony with the identified themes' recurrence by being closely related to the implementation phase. 


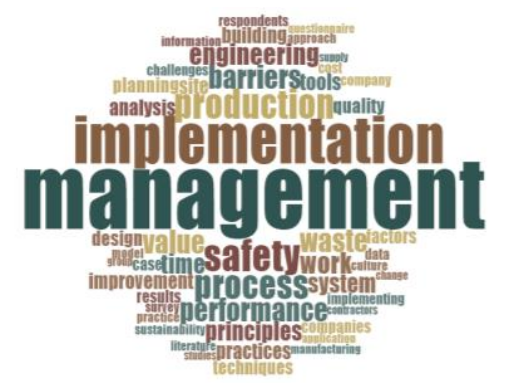

Figure 5- Most frequent words in all studies

\section{The Relationship Between the Configurations AND The Themes}

Figure 6 presents the frequency of the configurations in the sample along with their associated themes. As the figure shows, semi-elaborated studies were the most commonly-used configuration by comprising more than $80 \%$ of the sample. The most frequent themes in this category included implementation barriers, benefits, and success factors. Significant differences were observed between the contents of the simple configuration category and the elaborated studies. While investigating the success factors was found to be the most frequent theme in simple studies, the elaborated studies mainly involved proposing a model, framework, or approach.

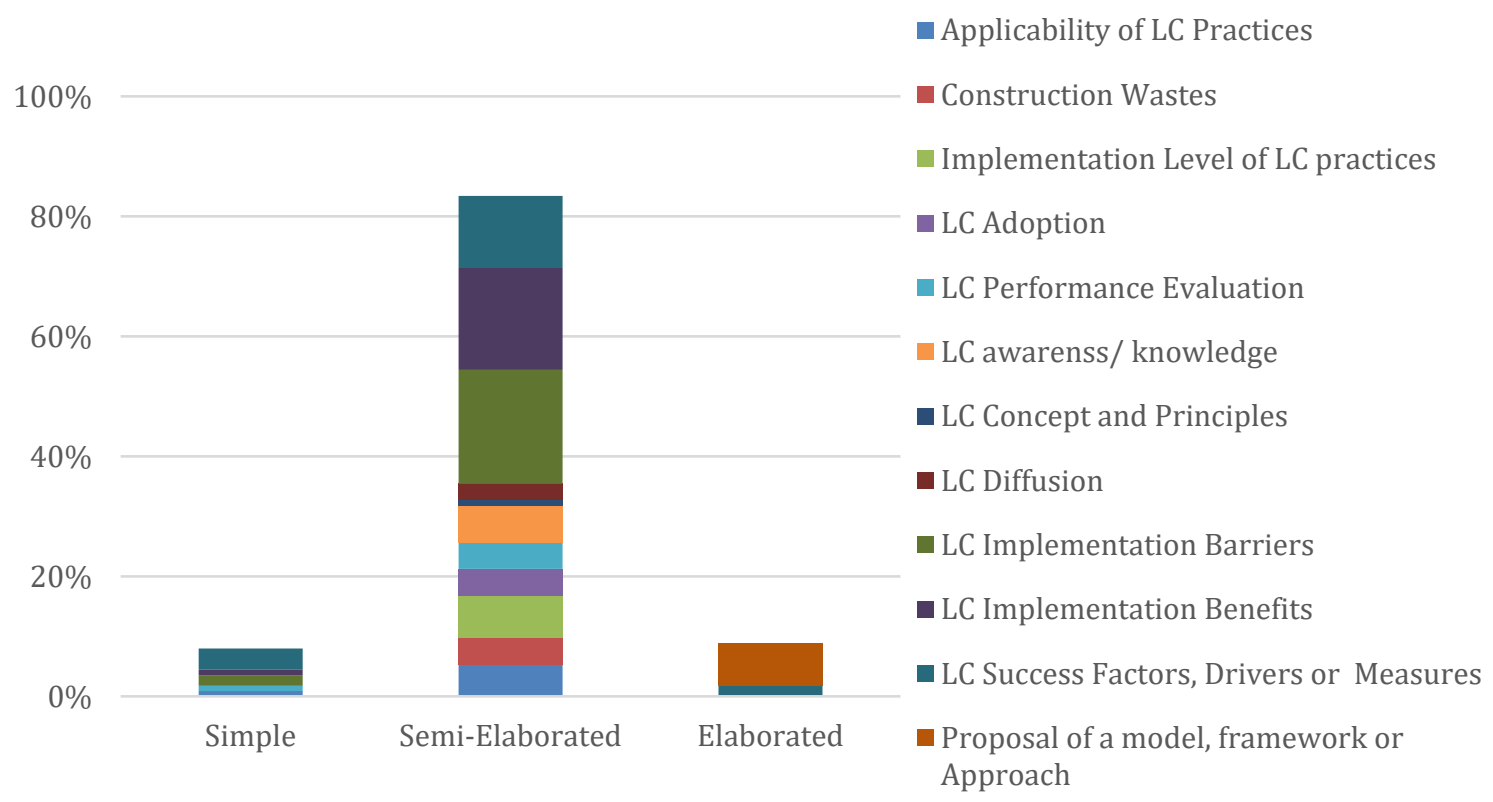

Figure 6- Themes of findings by study categories

A word frequency analysis was also conducted each for each study category. Figure 7 presents the word cloud chart generated to identify the most frequent words in each category of configuration. These charts represent both similarities and difference in the contents of the studies. These figures share the significance of the word "management" with figure 5. However, implementation was the most frequent word in studies with a simple configuration. Tools and practices were two aspects of implementation that turned to attract considerable attention in the simple configurations. Semi-elaborated studies were more concerned with managerial aspects such as process, waste, and production. The figures also show that safety and performance were two subjects that went through 
studies with elaborated configurations. In other words, these two subjects are ahead of the rest in being investigated extensively and in-depth.

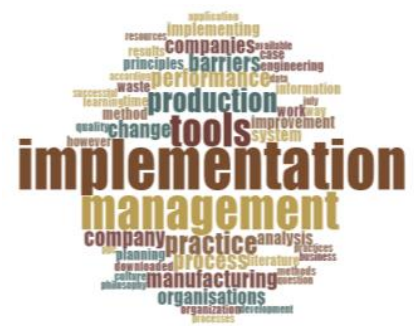

(a)

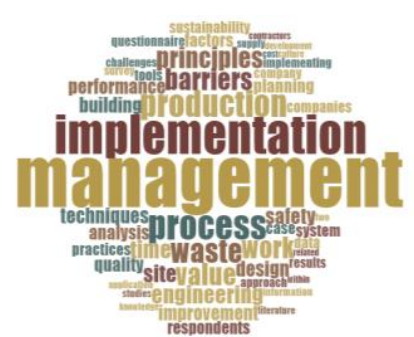

(b)

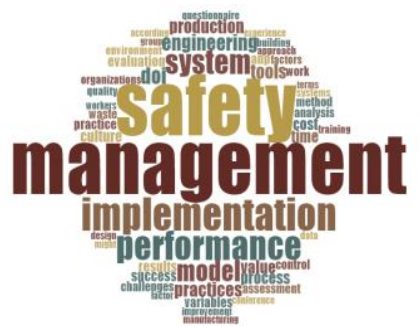

(c)

Figure 7- Most frequent words in: a) simple b) semi-elaborated and c) elaborated studies

Further, the average number of annual citations was used as an index to indicate the level of contribution made by each study configuration. The index was calculated for each study based on the number of citations divided by the number of years that they have been available to the research community. The results were averaged and grouped by each study configuration. Figure 8 indicates the result in which a considerable difference between the contribution level of simple studies and the other two categories can be seen.

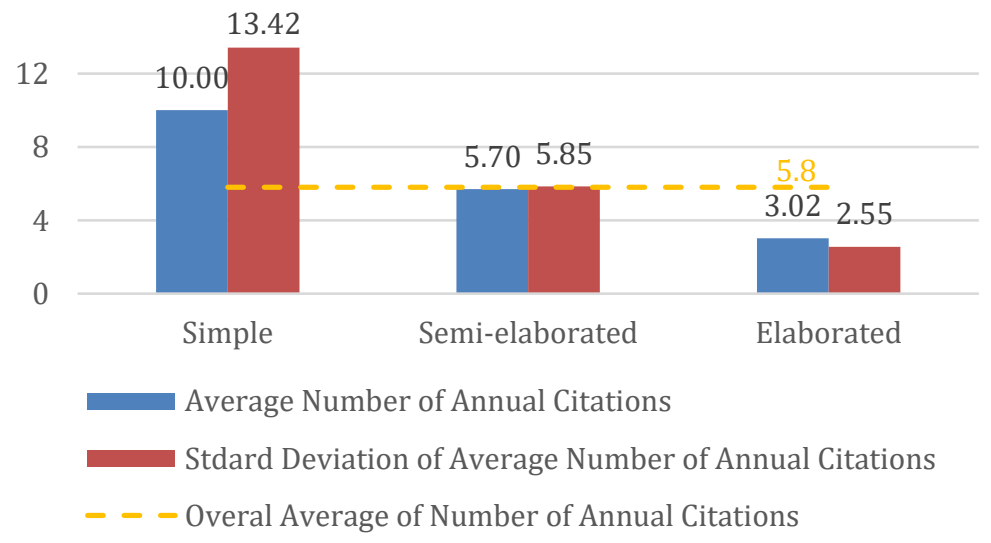

Figure 8 - The average of the annual number of citations by study configuration

\section{DISCUSSION}

According to the bibliographic information of the sample, survey research in Lean Construction is observing a significant increase in recent years. It can be associated with the technological improvement that facilitates sampling, communication and ultimately data collection. Furthermore, this growing trend indicates that the value of empirical data, especially survey research, is taking a more significant part in future research outcomes. Besides, the number of countries in the sample signals that Lean Construction is still early in its global hype cycle and far from a desirable state where Lean Construction is studied and practiced in the majority of countries of the world. Thus, researchers are urged to embark on international conjoint research to promulgate Lean Construction in new countries, enhance existing practices and eventually increase Lean Construction research diffusion.

The findings and content analysis of the publications indicated that while implementation issues have been widely investigated, less attention has been paid to 
diffusion and adoption issues. Given the fundamental importance of the later ones, a shift is demanded in the general focus of the lean construction research community.

A relationship was observed between the content of the studies and the configurations used in the study design. The configurations were divided into three groups of simple, semi-elaborated and elaborated study. A significant difference was observed between the density of the identified configuration, which indicates a low level of diversity in methods applied to the Lean Construction survey research. So far, most of the research completed in the community falls in the semi-elaborated category. The research also described the situation (the Whats) without elaborating the reasons for the observations (the Whys). Therefore, it seems that Lean Construction research is ready to move to the next level and to start developing studies with elaborated configurations. This demand is more evident for subjects such as success factors, barriers, and benefits in particular.

Lastly, the highest contribution of simple studies and the lowest level of elaborated ones could indicate the incompleteness of the former and strength of the later. Thus, more elaborated research is encouraged as it pushes the knowledge further towards its edge.

\section{CONCLUSION}

Identifying the active state and classification of the mechanisms used by the survey studies is crucial to improve the quality of future research. To achieve this, a total of 70 survey literature on Lean Construction were reviewed to elicit their bibliographic information, common components and content characteristics. It was found that seven common components form three different configurations in Lean Construction survey research. A thematic analysis of the result revealed twelve main themes in the sampled literature which was then used together with the average number of annual citations to establish the relationships between the identified configurations. The analysis of the data also shows that interest in survey research on Lean Construction is increasing and that the empirical data will be of higher value in future research. Further, researchers are encouraged to consider more diverse methods and elaborated configurations and also to direct their studies towards more fundamental issues such as diffusion and adoption.

This study uses a random sampling method to collect data. Future research may involve a systematic literature review to ensure of the involvement of all pertinent works.

\section{REFERENCES}

Abduh, M., and Roza, H. (2006). "Indonesian Contractors' Readiness Towards Lean Construction." 14th Annual Conference of the International Group for Lean Construction (IGLC14). Santiago, Chile, 543-549.

Alreck, P. L., and Settle, R. B. (1985). "The Survey Research Handbook. Homewood." McGraw-Hill/Irwin.

Aziz, R. F., and Hafez, S. M. J. A. E. J. (2013). "Applying Lean Thinking in Construction and Performance Improvement." Alexandria Engineering Journal, 52(4), 679-695.

Ballard, H. G. (2000). "The Last Planner System of Production Control." PhD Diss, University of Birmingham.

Bashir, A. M., Suresh, S., Oloke, D. A., Proverbs, D. G., and Gameson, R. (2013). "The Application of Lean Construction Tools in the United Kingdom Construction Organisations: Findings from A Qualitative Inquiry." AEI 2013: Building Solutions for Architectural Engineering, 64-73.

Biederman, I. (1987). "Recognition-by-components: A Theory of Human Image Understanding." Psychological Review, 94(2), 115. 
Bygballe, L. E., and Swärd, A. (2014). "Implementing Lean Construction: A Practice Perspective." 22nd Annual Conference of the International Group for Lean Construction (IGLC22). Oslo, Norway, 3-14.

Check, J., and Schutt, R. K. (2011). Research Methods in Education., Sage Publications. Egan, J. (1998). Rethinking construction, DETR.

Enshassi, A., and Abu Zaiter, M. (2014). "Implementation of Lean Tools on Safety in Construction Projects in Palestine." 22nd Annual Conference of the International Group for Lean Construction (IGLC22). Oslo, Norway, 1205-1218.

Ghosh, S., and Young-Corbett, D. (2009). "Intersection between Lean Construction and Safety Research: a Review of the Literature." Industrial Engineering Research Conference.

Heimerl, F., Lohmann, S., Lange, S., and Ertl, T. (2014). "Word Cloud Explorer: Text Analytics Based on Word Clouds." 2014 47th Hawaii International Conference on System Sciences, IEEE, 1833-1842.

Hox, J. J., and Boeije, H. R. (2005). "Data Collection, Primary Versus Secondary." Encyclopedia of Social Management, 1, 593-599.

Jasmine, K., and Vasantha, R. "Identification of Software Performance Bottleneck Components in Reuse Based Software Products with the Application of Acquaintanceship Graphs." Proc., International Conference on Software Engineering Advances (ICSEA 2007), IEEE, 34-34.

Koohestani, K., Poshdar, M., and Gonzalez, V. (2020). "Finding the Way to Success in Implementing Lean Construction in an Unfavourable Context." 28th Annual Conference of the International. Group for Lean Construction (IGLC28), International Group for Lean Construction (IGLC).

Koskela, L. J., and Howell, G. (2002). "The Underlying Theory of Project Management is Obsolete." PMI research conference, PMI, 293-302.

Li, X., Wang, X., and Lei, L. (2019). "The Application of an ANP-Fuzzy Comprehensive Evaluation Model to Assess Lean Construction Management Performance." Engineering, Construction and Architectural Management, 27(2).

Meng, X. (2019). "Lean Management in the Context of Construction Supply Chains." International Journal of Production Research, 57(11), 3784-3798.

Noble, H., and Smith, J. (2015). "Issues of Validity and Reliability in Qualitative Research." Evidence-based nursing, 18(2), 34-35.

Ponto, J. (2015). "Understanding and Evaluating Survey Research." Journal of the Advanced Practitioner in Oncology, 6(2), 168.

Rossi, P. H., Wright, J. D., and Anderson, A. B. (2013). Handbook of survey research., Academic Press.

Sapsford, R., and Jupp, V. (1996). Data Collection and Analysis., Sage.

Singleton, R., Straits, B., and Straits, M. (1999). "Approaches to Social Research." Oxford University Press, 9.

United Nations (2020). "World Economic Situation and Prospects 2020." United Nations Publications.

Zhong, Q.-Y., and Song, J. (2008). "The Developing Trend Research of Knowledge Management Overseas Based on Word Frequency Analysis." 4th International Conference on Wireless Communications, Networking and Mobile Computing, IEEE, $1-4$. 